\title{
JENIS DAN BENTUK PENGOBATAN PADA RELIEF CANDI BOROBUDUR
}

Oleh :

Wiwit Kasiyati, SS

Koordinator Pokja Pemeliharaan

Balai Konservasi Peninggalan Borobudur

Pada awalnya konsep tentang penyakit selalu dihubungkan dengan segala sesuatu yang tidak enak. Konsep ini menganggap keadaan sakit adalah kejadian yang dikehendaki oleh dewa-dewa penguasa dengan maksud tertentu atau balasan dari roh-roh jahat. Penyakit dapat juga timbul karena akibat fisik, tetapi pada dasarnya selalu dihubungkan dengan sesuatu yang tidak dapat dijelaskan dengan akal sehat, misalnya karena kekuatan black magic. Keadaan tersebut dianggap tidak dapat sembuh kecuali melakukan perbuatan yang juga tidak dapat dijelaskan dengan akal sehat, misalnya berhubungan dengan alam supranatural atau dengan memanggil dewa atau roh (Graeve, 1978:586).

Pada perkembangan berikutnya, konsep tentang penyakit mulai agak berubah. Manusia mulai menyadari bahwa penyakit disebabkan oleh alam, dimana mereka tidak dapat beradaptasi dengan baik (Risse, 1978:583). Ada pendapat yang mengatakan bahwa pengetahuan tentang obat-obatan di Indonesia sudah ada sebelum masuknya pengaruh India (Satyawati Sulaiman, 1986:177).

Pendapat tersebut mengatakan bahwa sebelum orangrang Indonesia dapat membaca dan menulis, sudah ada seorang pemimpin yang didampingi seorang pendeta untuk upacara-upacara dan scorang dukun untuk soal magis dan obat-obatan.

Pengetahuan tentang kesehatan semakin tampak pada masa Klasik. Berdasarkan data relief, prasasti, dan naskah kesusasteraan pada masa klasik menunjukkan adanıa protesi dibidang kesehatan. Dari data relect dapat diamati pada relicf Karmawibhangea Cand Borobudur terdapat panil ang menunjukkan adegan pertolongan terhadap orang sakit, rasa bersiukur atas kescmbuhan dart sakit, juga proses kclahiran vang dilakukan olch dukun beranak.
A. Data Relief
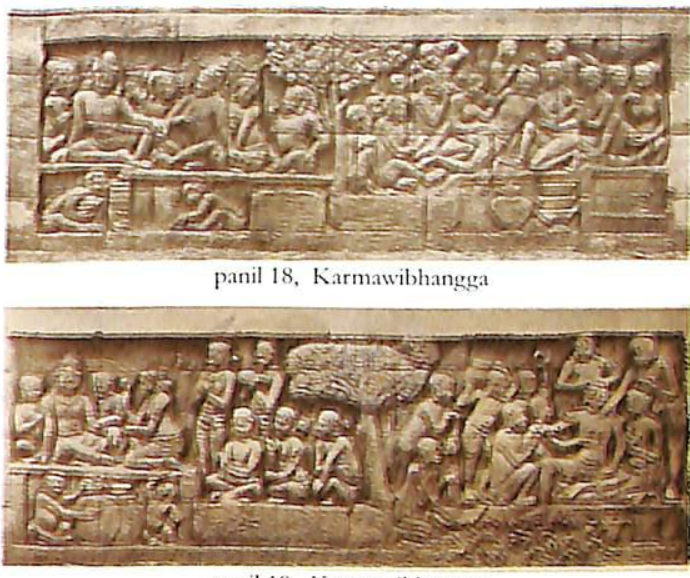

panil 19, Karmawibhangga

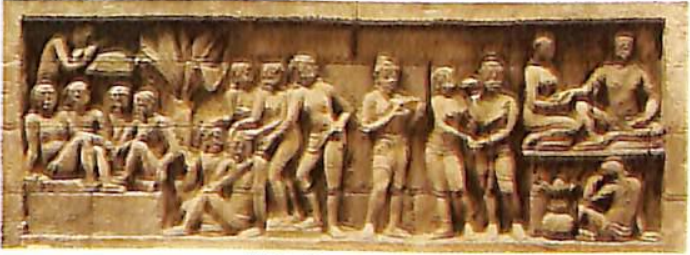

panil 78, Karmawibhangga

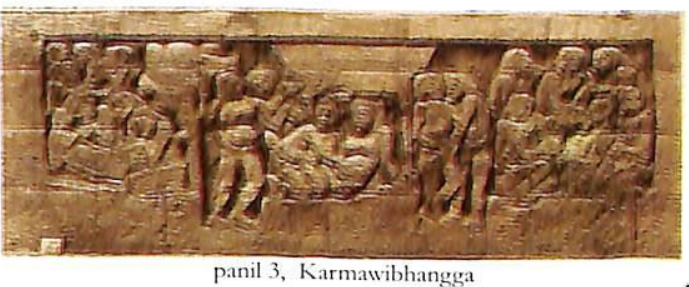

Data artefaktual di bidang kesehatan terutama mengenai pengobatan pada masa Jawa Kuna terdapat pada relief Karmawibhangga Candi Borobudur. Relief mempunyai maksud dan peranan penting dalam seni bangunan candi, relief sebagai media visual yang memiliki beberapa fngsi diantaranya fungsi edukatif. Fungsi edukatif ditunjukkan pada inti filosofi penggambaran relief yang berisikan tuntunan atau pendidikan moral bagi kehidupan manusia. Ungkapan unsurunsur pada relief dapat memberikan petunjuk tentang perkembangan budava, teknik, ieni, religi, keadaan sosial masa lalu, bahkan mengenai kesehatan masrarakat lawa kuna.

Pada relict Karmawibhangea panil le mengeambarkan sonrang bah-lati mendapat perawatan belecrapa wanta a da bane memifat kepalansa, menegang tangan dan kakins. () rane mane do sckermatampak bersedih.

Pada panil 19 menunjukkan ateenen beberapa orang yang sedang memberikan pertolongan pada seorang laki-laki yang sedang sakit. Ada yang memijat kepalanya, menggosok perut serta dadanya, juga ada seseorang yang membawa obat. Di sampingnya terdapat adegan yang memperlihatkan suasana bersyukur atas kesembuhan seseorang.

Pada panil 78 juga terdapat adegan yang sama yaitu seorang wanita sedang memegang lengan lakilaki yang sedang sakit, sementara adegan yang lain beberapa orang sedang mengobati dua orang laki-laki sakit kepala dengan cara memegang kepalanya.

Pada panil 3 terdapat adegan proses kelahiran, tampak seorang wanita hamil sedang dibantu beberapa wanita, diantaranya seorang dukun beranak. Relief kelahiran juga terdapat di Candi Brahma kompleks Candi Prambanan. Proses kelahiran tersebut digambarkan dibantu oleh seorang wanita yang dianggap sebagai dukun beranak.

\section{B. Data Prasasti}

Data prasasti tidak langsung menyebut tentang masalah kesehatan, melainkan hanya nama-nama profesi yang dapat dihubungkan dengan kesehatan. Dari data prasasti yang dikeluarkan pada sekitar abad XIV - XV M, terdapat namanama yang berhubungan dengan profesi kesehatan. Prasasti tersebut yaitu prasasti Balawi, Sidoteka, Bendosari, Biluluk, dan Madhawapura. Uraian isi prasasti-prasasti tersebut yaitu:

\section{Prasasti Balawi}

Prasasti Balawi berangka tahun 1305 M. Kutipan dari bagian prasasti tersebut adalah:

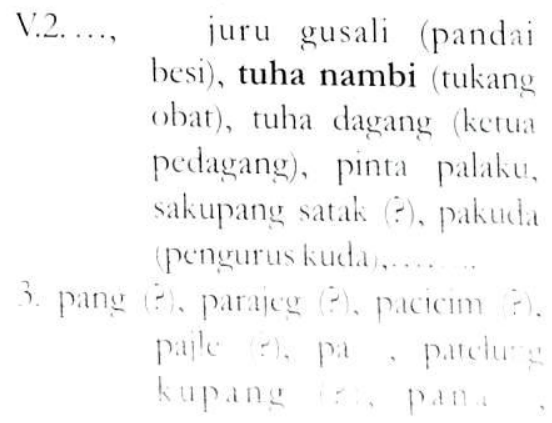




\section{Hasil Studi}

panakupang (?), paprayaccita (penjaga kebersihan upacara), kdi (dukun wanita), walyan (tabib), widu mangidung (penyanyi kidung), ....

\section{Prasasti Sidoteka}

Prasasti Sidoteka disebut juga prasasti Jayanegara II. Prasasti tersebut berangka tahun $1323 \mathrm{M}$. Kutipan dari bagian prasasti tersebut adalah:

6.b....,

tuha dagang (ketua pedagang), tuha nambi ( $\mathrm{tukang}$ obat), ...........................wli tamba (orang yang $m$ e $n$ g $\quad o$ b a $\quad t \quad$ penyakit), ......................

\section{Prasasti Bendosari}

Prasasti Bendosari disebut juga prasasti Manah i Manuk dan prasasti Javasong. Prasasti Bendosari berangka tahun 1360 M. Kutipan dari bagian prasasti tersebut adalah:

5. kepada orang-orang tua dalam pertapaan di Pakandangan, sebidang sawah 16 lirih (satuan ukuran luas tanah), kepada lingkaran perdikan di Kuku 2 lirih, kepada janggan (tabib desa) di

\section{Prasasti Biluluk}

Prasasti Biluluk berasal dari masa pemerintahan raja Hayam Wuruk $(1350 \mathrm{M}-1389 \mathrm{M})$ dan Wikramawardhana (1389 M - 1429 M). Kutipan dari bagian prasasti tersebut adalah:

Sisi muka :

4. “ ..., selanjutnya segala penjaga tanah perdikan yang menjalankan usaha pekerjaan, semuanya masing-masing satu, mereka itu dibebaskan dari segala macam beban bea dan cukai, vaitu (rang berkaitan dengan) padadah (pemijatan), pawiwaha (perkawinan),

\section{Prasasti Madhawapura}

Prasasti Madhawapura tidak berangka tahun, akan tetapi dari gava bahasanya dapat diketahui dari masa kerajaan Najapahit. Kutipan dari bagian prasasti terschut adalah: Sisi muka:

2. pembuat pakaian (abhasana) tiga dasar (ukuran), angawari dasar (ukuran), angawari (pembuat kuali) acaraki (penjual jamu), ....

\section{Data Naskah Kesusasteraan}

Data naskah kesusasteraan kutipan isinya lebih jelas menyebut tentang profesi kesehatan, berbagai jenis penyakit, dan obat-obatan untuk menyembuhkan penyakit. Naskah kesusastraan periode Jawa Timur pada abad XIV - XV M terdapat kutipan pada bagian cerita yang menunjukkan kegiatan dibidang kesehatan yaitu kitab Agama, Sarasamuccaya, Rajapatigundala, Korawacrama, dan Pararaton. Uraian isi naskah kesusasteraan tersebut yaitu:

\section{Kitab Agama}

Kitab Agama disebut juga kitab Kutaramanawa. Kitab ini berasal dari masa pemerintahan Rajasanegara (Slamet Muljana, 1967: 10). Kutipan dari masing-masing pasal tersebut:

62. "Barang siapa kena perang akibat kelalaian, karena yang memerang tidak sengaja atau tidak tahu, jika tidak menderita luka atau sakit, yang memerang itu tidak dikenakan denda. Jika yang kena perang itu menderita luka, supaya yang memerang membayar uang pembeli obat cukup sampai lukanya sembuh, dan dikenakan denda lima ratus oleh raja yang berkuasa".

113. "Seorang gadis berhak $\mathrm{m}$ e $\mathrm{mb}$ a t a l k a perkawinannya, setelah di tempat tidur mengetahui bahwa lakinya menderita penyakit (yang me $n g u r u g k a n$ perkawinan) misalnya sakit kuming, impoten untuk persetubuhan, bukan lakilaki (banci), mempunyai penyakit budug pada perut, pada paha, pada pantat, tidak kelihatan dari luar; menderita sakit ayan atau gila. Dalam hal vang demikian itu gadis tersebut berhak untuk membatalkan perkawinannya. Ia wajib mengembalikan tukon tanpa lipat dua".

19(). "Jika ada orang menchang pohon, menjatuhi orans atau melempar tidak dengan sengaja kena orang atau binatang, kemudian mengatakan bahwa itu adalah kesalahan orang yang kena lemparan atau tertimpa pohon, ..., jika orang yang kena lemparan atau tertimpa pohon itu menderita luka supaya penebang itu memberi uang pembeli obat hingga pulih kembali lukanya kepada si penderita, dan dikenakan denda lima tali oleh raja yang berkuasa sebagai penebus tangannya. Jika orang yang tertimpa pohon itu meninggal, supaya penebang itu memberikan uang pakuramas..."

274. "Jika ada orang yang mengobati t a n a memiliki pengetahuan tentang obatobatan, tanpa mengetahui mantra yang banyak, tanpa mengetahui soal penyakit, hanya karena menghendaki hadiah dari orang yang sakit, orang yang demikian supaya diperlakukan sama dengan pencuri . Pengobatan yang demikian tidak akan berhasil. Jika dia mengobati binatang, dan akhirnya binatang itu mati, supaya dikenakan denda empat kali tiga atak. Jika mengobati orang, karenanya tidak menjadi sembuh kemudian malah mati, dendanya selaksa, jika mengobati brahmana, karenanya tidak sembuh malah mati, vang mengobati dikenakan pidana mati oleh raja yang berkuasa. Demikianlah ketetapan undang-undang".

\section{Kitab Sarasamuccaya}

Kitab Sarasamuccava adalah salah satu kitab hukum pada masa Majapahit. Di dalam kitab ini terdapat keterangan vang berhubungan dengan masalah keschatan, Kutipan dari bagian tersebut yaitu:

168." Demikian perincian yang dinamakan temannsa, saitu, seorang pedagang, temannsa adalah pedagang (pembeli), (dan) juragan, sahabat bagi seorang pengembara, perpisahan (an) beriauhan, sahabat bagi orang berumah tangga 
bagi orang berumah tangga istrinya itulah, sedangkan orang yang sakit, walyan (tabib), mamimami (pembuat obat-obatan), sahabatnya, apa pun orang yang mampir akan mati, sedekah (amal kebajikan) sebagai temannya".

234. “ ..., bhrunaha (menggugurkan kandungan), singkatnya sangat besar dosa orang itu".

325. "Inilah macamnya orang yang tidak pantas dijadikan kawan bergaul, yaitu pisakit (orang yang menyebabkan orang lain sakit atau menderita, misalnya dengan melakukan guna-guna), ...".

369. " Tidak ada obat, tidak ada mantra, tidak ada persembahan, tidak ada japa, yang mampu menolong, membebaskan seseorang dari kematian itu, atau dapat menangkis maut itu, sia-sialah ucapan mantra yang berulang-ulang yang disebut japa itu”.

501. “ ..., sebaliknya obat yang berempah-rempah, minyak, gulika, akar, dipergunakan mengobati sakitnya badan, lenyap karenanya, kekuatan ilmu melebihi kekuatan badan, kesaktian tubuh".

\section{Kitab Rajapatigundala}

Kitab Rajapatigundala merupakan salah satu kitab dari masa Majapahit. Pada bagian sapatha disebut nama-nama penyakit yang akan menimpa orang yang tidak mematuhi hukum yang telah ditetapkan. Kutipan dari bagian tersebut adalah:

17.a. " ..., untuk orang yang tidak mematuhi, dia akan mendapat kesengsaraan, ..., hidup mereka akan tanpa mendapat kesehatan, mereka akan sakit kusta, tidak dapat melihat dengan sempurna, sakit gila, cacat mental, buta, bungkuk. Maka semua orang yang tidak mematuhi akan dikutuk oleh raja Patigundala yang suci,

b. maka terjadilah, semua kesengsaraan, sakit dan penyakit akan diderita oleh orang yang tidak mematuhi, tidak ada kemungkinan untuk diobati, untuk selamalamanya mereka akan menderita. Ini adalah kutukan cri bhagati yang patut dihormati, seorang ratu pada masanya, untuk seluruh pulau Jawa, ...”.

\section{Kitab Korawacrama}

Kit a b Koraw a crama diperkirakan berasal dari abad XIV M. Kutipan dari bagian tersebut adalah:

23. " "..., terkejutlah Bhattara guru ketika melihat manusia, ternyata banyak yang menderita sakit, ada wudug (lepra), ana buyan (gila), ana wiket (mempunyai banyak luka), pincang welu (hernia), beser (selalu ingin buang air), turuh (kerusakan pada salah satu organ tubuh), apus (kehilangan tenaga), wuta (buta), tuli (tuli), bisu (bisu), barah (lepra yang sudah parah), uleren (cacingan), umis (pendarahan), lampang (sejenis penyakit kulit), bule (albino), gondong (leher membengkak), amis antem (berbau amis), masegir (berbau tidak enak), apek (berbau apek), demikian keadaan manusia,...".

30. " ".., berlarilah Bhattara Cri dengan Bhattara Wisnu masuk ke dalam rumah acaraki (penjual jamu), pucat pasilah mukanya, dia sedang menggiling bahan untuk wangi-wangian, ..., pucatlah sang macaraki, ...".

\section{Kitab Pararaton}

Kitab Pararaton berbentuk prosa dan digubah pada akhir abad XV M. Kutipan dari bagian tersebut adalah:

27. " ... Ketika itu raja Jayanegara sedang gering tidak keluar dari istana karena di badannya tumbuh bisul (bubuhen). Tanca diperintahkan untuk mengoperasi bisul tersebut di peraduan. Dua kali dibedah tetapi tidak berhasil. Akhirnva Tanca memohon agar sang raja segera menanggalkan kemitannya. Raja pun menurut dan melepasnya, kemudian diletakkan di atas peraduan. Tanca lalu membedah bisul tersebut lalu diambil penyakitnya, ...".

\section{Jenis-Jenis Penyakit dan Pengobatannya}

Pada masa Klasik sistem kesehatan pada umumnya terdiri dari suatu sistem teori penyakit dan sistem perawatan kesehatan. Sistem teori penyakit meliputi kepercayaan mengenai ciri-ciri sehat, sebab-sebab sakit, pengobatan, dan teknik penyembuhan. Dalam teori penyakit terdapat konsep dasar yang dapat dibedakan menjadi dua yaitu teori personalistik dan teori naturalistik. Teori personalistik didasari anggapan adanya kekuatan supranatural, sedangkan teori naturalistik mengakui adanya suatu model keseimbangan, apabila keseimbangan terganggu maka akan timbul penyakit (George M. Foster dan Barbara Gallatin, 1986: 46-47).

Pada teori personalistik, secara umum jenis-jenis penyakit yang dikenal pada masyarakat Jawa Kuna pada abad XIV - XV M disebabkan oleh kuasa dewadewa dan kuasa makhluk jahat. Penyakit yang disebabkan oleh kuasa dewa-dewa seperti dalam prasasti Surodakan, beberapa jenis penyakit disebutkan pada bagian sapatha atau kutukan. Penyakitpenyakit tersebut akan diderita oleh orang yang melanggar aturan. Penyakit akibat kutukan dikatakan tidak akan dapat diobati dan untuk selamanya akan menderita.

Pada teori naturalistik, sebabsebab sakit berhubungan dengan keadaan sehat. Penyakit disebabkan karena tidak adanya keseimbangan cairan dalam tubuh manusia. Selain karena tidak adanva keseimbangan cairan, penyakit dapat disebabkan pula karena adanya gangguan atau kerusakan bagian tubuh tertentu sehingga tidak dapat berfungsi sebagaimana mestinya. Termasuk dalam jenis penyakit ini adalah awatuk (batuk), bhara gigil (panas dingin), karis (sakit kepala), bubuhen (bisulan), umis (pendarahan), uleren (cacingan), dan slema (batuk berlendir).

Penyakit-penyakit tersebut di ata: karena disebabkan oleh ketidak seimbangan dalam tubuh manusia, maka pengobatannya bertujuan untuk mengembalikan keseimbangan tubuh Selain menggunakan ramuan obat, pengobatan penyakit naturalistik juga mempercayai adanva kekuatan di luar kemampuan manusia vang dapat membantu proses penyembuhan. Hal 


\section{Kitab Rajapatigundala}

Kitab Rajapatigundala merupakan salah satu kitab dari masa Majapahit. Pada bagian sapatha disebut nama-nama penyakit yang akan menimpa orang yang tidak mematuhi hukum yang telah ditetapkan. Kutipan dari bagian tersebut adalah:

17.a. “ ..., untuk orang yang tidak mematuhi, dia akan mendapat kesengsaraan, ..., hidup mereka akan tanpa mendapat kesehatan, mereka akan sakit kusta, tidak dapat melihat dengan sempurna, sakit gila, cacat mental, buta, bungkuk. Maka semua orang yang tidak mematuhi akan dikutuk oleh raja Patigundala yang suci,

b. maka terjadilah, semua kesengsaraan, sakit dan penyakit akan diderita oleh orang yang tidak mematuhi, tidak ada kemungkinan untuk diobati, untuk selama-lamanya mereka akan menderita. Ini adalah kutukan cri bhagati yang patut dihormati, seorang ratu pada masanya, untuk seluruh pulau Jawa, ...".

\section{Kitab Korawacrama}

$\mathrm{K}$ i t a b Korawa c r m a diperkirakan berasal dari abad XIV M. Kutipan dari bagian tersebut adalah:

23. " ..., terkejutlah Bhattara guru ketika melihat manusia, ternyata banyak yang menderita sakit, ada wudug (lepra), ana buyan (gila), ana wiket (mempunyai banvak luka), pincang welu (hernia), beser (selalu ingin buang air), turuh (kerusakan pada salah satu organ tubuh), apus (kehilangan tenaga), wuta (buta), tuli (tuli), bisu (bisu), barah (lepra yang sudah parah), uleren (cacingan), umis (pendarahan), lampang (sejenis penyakit kulit), bule (albino), gondong (l cher m(mbengkak), amis antem (borbau amis), masegir (berbau tidak cnak), apek (berbau apek), demikian kcadaan manusia,..." masuk ke dalam rumah acaraki (penjual jamu), pucat pasilah mukanya, dia sedang menggiling bahan untuk wangi-wangian, ..., pucatlah sang macaraki, ...”.

\section{Kitab Pararaton}

Kitab Pararaton berbentuk prosa dan digubah pada akhir abad XV M. Kutipan dari bagian tersebut adalah:

27. " ... Ketika itu raja Jayanegara sedang gering tidak keluar dari istana karena di badannya tumbuh bisul (bubuhen). Tanca diperintahkan untuk mengoperasi bisul tersebut di peraduan. Dua kali dibedah tetapi tidak berhasil. Akhirnya Tanca memohon agar sang raja segera menanggalkan kemitannya. Raja pun menurut dan melepasnya, kemudian diletakkan di atas peraduan. Tanca lalu membedah bisul tersebut lalu diambil penyakitnya, ...".

\section{Jenis-Jenis Penyakit dan Pengobatannya}

Pada masa Klasik sistem kesehatan pada umumnya terdiri dari suatu sistem teori penyakit dan sistem perawatan kesehatan. Sistem teori penyakit meliputi kepercayaan mengenai ciri-ciri sehat, sebab-sebab sakit, pengobatan, dan teknik penyembuhan. Dalam teori penyakit terdapat konsep dasar yang dapat dibedakan menjadi dua yaitu teori personalistik dan teori naturalistik. Teori personalistik didasari anggapan adanya kekuatan supranatural, sedangkan teori naturalistik mengakui adanya suatu model keseimbangan, apabila keseimbangan terganggu maka akan timbul penyakit (George M. Foster dan Barbara Gallatin, 1986: 46-47).

Pada teori personalistik, secara umum jenis-jenis penvakit yang dikenal pada masyarakat Jawa Kuna pada abad XIV - XV M disebabkan oleh kuasa dewadewa dan kuasa makhluk jahat. Penyakit yang disebabkan oleh kuasa dewa-dewa seperti dalam prasasti Surodakan, beberapa jenis penyakit disebutkan pada bagian sapatha atau kutukan. Penvakitpenyakit tersebut akan diderita oleh orang yang melanggar aturan. Penyakit akibat kutukan dikatakan tidak akan dapat diobati
Pada teori naturalistik, sebabsebab sakit berhubungan dengan keadaan sehat. Penyakit disebabkan karena tidak adanya keseimbangan cairan dalam tubuh manusia. Selain karena tidak adanya keseimbangan cairan, penyakit dapat disebabkan pula karena adanya gangguan atau kerusakan bagian tubuh tertentu sehingga tidak dapat berfungsi sebagaimana mestinya. Termasuk dalam jenis penyakit ini adalah awatuk (batuk), bhara gigil (panas dingin), karis (sakit kepala), bubuhen (bisulan), umis (pendarahan), uleren (cacingan), dan slema (batuk berlendir).

Penyakit-penyakit tersebut di atas karena disebabkan oleh ketidakseimbangan dalam tubuh manusia, maka pengobatannya bertujuan untuk mengembalikan keseimbangan tubuh. Selain menggunakan ramuan obat, pengobatan penyakit naturalistik juga mempercayai adanya kekuatan di luar kemampuan manusia yang dapat membantu proses penyembuhan. Hal tersebut terlihat dengan digunakannya mantera-mantera yang dianggap mempunyai kekuatan qaib.

Pada relief Karmawibhangga tampak adegan seorang laki-laki sedang mendapat perawatan beberapa wanita dengan dipijat kepalanya (mungkin oleh padadah orang yang pekerjaannya memijat). Adegan yang lainnya beberapa orang sedang memberikan pertolongan pada seorang laki-laki yang sedang sakit dengan memijat kepalanya (padadah), menggosok perut serta dadanya dengan ramuan obat. Dapat dikatakan adegan tersebut adalah proses penyembuhan dengan ramuan obat karena tampak pula seseorang yang sedang membawa obat atau mungkin wli tamba orang yang pekerjaannya membuat obat. Dengan demikian proses pembuatan obat pun pastinya dengan menggunakan batu pipisan untuk menghaluskan ramuan obat tersebut. Alat semacam pipisan terdapat pada panil 19, seseorang tampak duduk di depannya terlihat benda dengan bentuk seperti pipisan. Kemungkinan orang tersebut sedang membuat ramuan jamu dengan cara dihaluskan dengan alat batu pipisan.

Tidak kalah menarik pada relief Karmawibhangga terdapat adegan proses kelahiran. Pada relief tersebut tampak secrang wanita hamil sedang dibantu beberapa wanita, diantaranya seorang dukun beranak (kdi). Penggambaran proses kelahiran tersebut oleh beberapa ahli diartikan pula sebagai proses aborsi karena merupakan hasil prostitusi. Apabila dicermati, relief Karmawibhangga yang 


\section{Hasil Studi}

membantu proses penyembuhan. Hal tersebut terlihat dengan digunakannya mantera-mantera yang dianggap mempunyai kekuatan qaib.

Pada relief Karmawibhangga tampak adegan seorang laki-laki sedang mendapat perawatan beberapa wanita dengan dipijat kepalanya (mungkin oleh padadah orang yang pekerjaannya memijat). Adegan yang lainnya beberapa orang sedang memberikan pertolongan pada seorang laki-laki yang sedang sakit dengan memijat kepalanya (padadah), menggosok perut serta dadanya dengan ramuan obat. Dapat dikatakan adegan tersebut adalah proses penyembuhan dengan ramuan obat karena tampak pula sescorang yang sedang membawa obat atau mungkin wli tamba orang yang pekerjaannya membuat obat. Dengan demikian proses pembuatan obat pun pastinya dengan menggunakan batu pipisan untuk menghaluskan ramuan obat terscbut. Alat semacam pipisan terdapat pada panil 19 , seseorang tampak duduk di depannya terlihat benda dengan bentuk seperti pipisan. Kemungkinan orang tersebut sedang membuat ramuan jamu dengan cara dihaluskan dengan alat batu pipisan.

Tidak kalah menarik pada relief Karmawibhangga terdapat adegan proses kelahiran. Pada relief tersebut tampak scorang wanita hamil sedang dibantu beberapa wanita, diantaranya seorang dukun beranak (kdi). Penggambaran proses kelahiran tersebut oleh beberapa ahli diartikan pula sebagai proses aborsi karena merupakan hasil prostitusi. Apabila dicermati, relief Karmawibhangga yang menggambarkan kehidupan manusia yang masih terikat oleh nafsu duniawi, maka di sana semua aspek kehidupan manusia baik yang bagus maupun yang buruk tercerminkan di relief ini. Proses aborsi atau menggugurkan kandungan semakin tcrlihat pada masa Majapahit, tcrbukti dari isi kitab Sarasamuccaya, terdapat kata bhrunaha (menggugurkan kandungan) merupakan dosa yang sangat besar bagi orang yang tega melakukannya.

\section{E. Bentuk-Bentuk Pengobatan}

Dari adanya jenis-jenis penyakit rang ada tentunia memerlukan penyembuhan atau pengobatan agar pengakit tersebut hilang. Proses penyembuhan dapat dibedakan menjacli cmpat cara yaitu cara magis, keagamaan. tisik, dan obat-obatan. Pengebatan dengan cara magis dilaksanakan dengan menggunakan mantera-mantera, cara keagamaan dengan mengadakan upacara ritual, cara fisik dengan memijat atau mengurut, dan cara obat-obatan dengan menggunakan khasiat bahan-bahan alami seperti tumbuh-tumbuhan dan binatang. Pengobatan dengan cara magis dan ritual keagamaan biasanya dilakukan untuk jenisjenis penyakit yang disebabkan oleh perantara atau kuasa supranatural, sedangkan pengobatan dengan cara fisik dan obat-obatan dilakukan untuk jenisjenis penyakit karena ketidakseimbangan dalam tubuh manusia.

Pengobatan secara magis caranya dengan membaca mantera-mantera yang dianggap mempunyai kekuatan qaib. Pembacaan mantera-mantera ini ditujukan kepada kekuatan dewa-dewa atau kekuatan lainnya yang menguasai dunia. Pengobatan sccara keagamaan biasanya dalam bentuk upacara ritual dengan melarung sesajian di laut diikuti dengan doa-doa agar penyakit yang diderita seseorang sembuh dengan memberikan sesajian di laut. Pengobatan secara fisik dengan melakukan pemijatan atau pengurutan yang dilakukan oleh padadah. Sebagai seorang penyembuh, padadah menggunakan sarana pemijatan. Pengobatan dengan bentuk pijat biasanya menggunakan ramuan yang dilumatkan kemudian dioleskan pada anggota badan yang salah uratnya. Dalam melakukan pemijatan tersebut menggunakan minyak atau ramuan lainnya untuk memudahkan proses pemijatan. Pengobatan dengan cara obat-obatan dilakukan dengan memberikan obat-obatan yang dibuat dari bahan alami terutama tumbuhan yang diketahui mempunyai khasiat tertentu untuk mengembalikan kescimbangan dalam tubuh.

\section{F. Profesi di Bidang Kesehatan}

Sistem perawatan keschamn adalah suatu pranata sosial yang melibatkan interaksi antara scjumlah orang, paling tidak antara pasien dan penrembuh. Pada dasarnya profesi vane bekerja untuk menyembuhkian masalahmasalah keschatan dapat diklasifikasikan monjadi tabib, ahli ramuan, dukun bari. dan tukang pijat. Dari data arkcoldeg vange ada, terdapat bansak protesi lang berbubungan dengan prose penyembuhan dalam masyarakat lama kuna. Protesi keschattan rersethut ad:alah walyan, kdi, tuha nambi, wli tamba, janggan, padadah, mamimami, dan acaraki. Dilihat dari arri masing-masing profesi rersebut, maka profesi keschatan dapat dikelompokkan menurut fungesma vaitu perawa keschatan tabih ataldokter dan pembuat obat. Termasuk dalam kelompok perawat kesehatan yaitu janggan, kdi, padadah, dan walyan, sedangkan kelompok pembuat obat yaitu acaraki, mamimami, tuha nambi, dan wli tamba.

Arti profesi kesehatan pada masvarakat Jawa Kuna adalah walyan artinya tabib atau dokter yang menggunakan kuasa qaib atau sihir (arti lainnya orang yang menguasai pengetahuan tentang tumbuh-tumbuhan sebagai obat ), kdi artinva dukun wanita, yang membantu proses kelahiran seorang bayi, tuha nambi artinya tukang obat atau orang yang tugasnya membuat ramuan obat-obatan, wli tamba artinva orang vang pekerjaannya membuat ramuan obatobatan, janggan artinya orang yang menguasai pengetahuan tentang penggunaan tumbuhan (arti lainnya adalah tabib desa atau dokter desa), padadah artinya orang yang pekerjaannya memijat untuk memulihkan kesehatan, mamimami artinya tukang pembuat obat, acaraki artinya orang vang menciptakan ramuan obat-obatan (arti lainnya penjual obat atau jamu). $\otimes$

\section{Daftar Pustaka}

G. Pudja. 1983. Manawa Dharma Sastraa: Weda Smrti Compendium Hukum Hindu. Jakarta: Proyek Pengadaan Kitab Suci Hindu Departemen Agama Republik Indonesia.

Graeve, Frank de. 1978. "Religion Concepts", Encyclopedia of Bioethics. I.G.A.G. Putra dan I llayan Sadia, Wrhaspati-tattwa. Jakarta: Yayasan Dharma Sarathi.

Nico S. Kalangie. 1981/1982. "Peranan dan Sumbangan Antropologi dalam Bidang Pclayanan Keschatan: Suatu kerangka Masalah-.Masalah Penclitian, Analisis Kebudayaan, Th. II. No. 1. Jakarta: Departemen Pendidikan dan Ricbudavaan.

Pungkic I.clly Kumarasari. 1\%)1. Sistem Kesehatan Dalam Masvarakat Jawa Kuna Pada Abad XIV Sampai XV Masehi: Kajian Berdasarkan Data Tertulis. Congakarta: Takultas Sartr. I niversitas (jadjah . Mactat

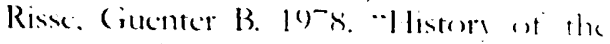
cincepts". Encyclopedia of Bioethics.

Samawati sulaman. lose. "lacal (enme Paala Vasal Klask". Kepribadian Kebudayaan Bangsa. lak.1m!.. Pustakia jara.

Slamee Vulianat 190- Perundangundangan Madjapahit. I.akint. Bhratara.

liker. Iarro I I | MSI. Farmakognosi. u

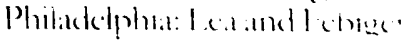

